\title{
AEROMAGNETIC MAP OF THE MIDDLETOWN QUADRANGLE, MIDDLESEX, HARTFORD, AND NEW HAVEN COUNTIES, CONNECTICUT
}

\author{
GEOPHYSICAL INVESTIGATIONS
}

MAP GP-856

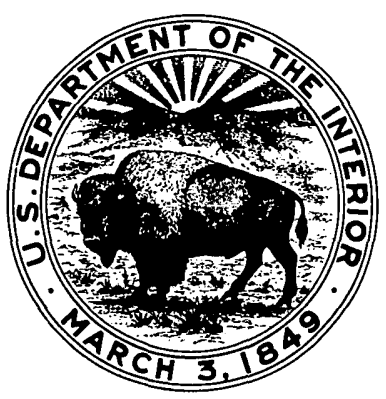

